\title{
Association of Hyperparathyroidism and Papillary Thyroid Cancer: A Multicenter Retrospective Study (Endocrinol Metab 2020;35:925-32, Chaiho Jeong et al.)
}

\author{
Chaiho Jeong, Jeonghoon Ha, Moo Il Kang
}

Division of Endocrinology and Metabolism, Department of Internal Medicine, Seoul St. Mary's Hospital, College of Medicine, The Catholic University of Korea, Seoul, Korea

We have received a letter from Candemir et al. regarding our recently published article [1]. We would like to present our opinions on several important comments made by Candemir et al. We reported a study to raise awareness regarding the need for papillary thyroid cancer (PTC) screening in patients with hyperparathyroidism, and Candemir et al. agreed with our efforts. We would like to share our specific responses below.

\section{How was secondary hyperparathyroidism diagnosed?}

We selected patients with secondary hyperparathyroidism by defining the condition conventionally, as hypocalcemia and elevated parathyroid hormone (PTH) levels in patients with chronic kidney disease. A retrospective chart review was used to select patients with simultaneous calcium and PTH measurements.

\section{How many of these patients were on dialysis, and was there a relationship between the disease duration and concurrent PTC?}

Among 125 patients with secondary hyperparathyroidism, 11 were on dialysis. However, this is not a meaningful figure in terms of the course of the disease due to the retrospective nature of the study. Since this study focused specifically on patients who underwent parathyroidectomy, it did not sufficiently reflect temporal changes. In addition, it was difficult to ascertain precisely when the patients were diagnosed with hyperparathyroidism.

\section{How was the decision of thyroidectomy made in patients} without fine-needle aspiration, and which criteria were used for central dissection decision in these patients?

Fine-needle aspiration was performed for all suspicious nodules, and the Korean Thyroid Imaging Reporting and Data System (K-TIRADS) was used to classify preoperative thyroid nodules for biopsy recommendation [2]. In accordance with the guidelines, biopsies were performed for K-TIRADS 5 nodules, even for lesions smaller than $1 \mathrm{~cm}$. The final diagnosis was based on a postoperative pathology review. Prophylactic central neck lymph node dissection was the standard surgical procedure for lymph node dissection at our institution.

\section{Copyright $\odot 2021$ Korean Endocrine Society}

This is an Open Access article distributed under the terms of the Creative Commons Attribution Non-Commercial License (https://creativecommons.org/ licenses/by-nc/4.0/) which permits unrestricted non-commercial use, distribution, and reproduction in any medium, provided the original work is properly cited.

\section{Moo Il Kang}

Division of Endocrinology and Metabolism, Department of Internal Medicine, Seoul St. Mary's Hospital, College of Medicine, The Catholic University of Korea, 222 Banpo-daero, Seocho-gu, Seoul 06591, Korea

Tel: +82-2-2258-6372, Fax: +82-2-599-3589, E-mail: mikang@catholic.ac.kr 


\section{Could it be said that mutation positivity in patients with} unknown $B R A F$ mutation may be responsible for the aggressive course of the concomitant PTC group?

This is an important and interesting point. Korean patients exhibit the highest rate of B-type Raf kinase (BRAF)-associated thyroid cancers worldwide [3]. Unfortunately, the fact that eight patients did not undergo mutation analysis may hinder a clearer explanation. It was difficult to tell whether $B R A F$ mutation was responsible for the aggressive course of concomitant PTC because we lacked the $B R A F$ mutation data in these patients with concomitant PTC. Although this suggestion is thought-provoking, we cannot reach a definitive conclusion. TERT mutations, which are commonly analyzed, have been shown to be closely related to aggressiveness [4]. Confirming the TERT analysis results will be another interesting research topic.

\section{Could there be more lymph node metastasis and extrathyroidal extension related to aggressive histological patterns in concomitant PTC?}

In cases of concomitant PTC $(n=23)$, the classic type $(n=18)$, follicular variant $(n=4)$, and tall cell variant $(n=1)$ were identified. The results of the comparison with classical PTC are as follows (Table 1).

Classic-type PTC was the most commonly identified type in both groups, and there was no difference in terms of histologic

\begin{tabular}{|c|c|c|c|}
\hline & $\begin{array}{c}\text { Concomitant PTC } \\
(n=23)\end{array}$ & $\begin{array}{c}\text { Classical PTC } \\
(n=98)\end{array}$ & $P$ value \\
\hline PTC subtype & & & NS \\
\hline Classic & $18(78.3)$ & $79(80.6)$ & \\
\hline Follicular variant & $4(17.4)$ & $16(16.3)$ & \\
\hline Tall cell variant & $1(4.3)$ & $3(3.1)$ & \\
\hline
\end{tabular}

Values are expressed as number (\%).

PTC, papillary thyroid cancer; NS, not significant. subtype.

The current study evaluated the incidence of concomitant PTC in patients with hyperparathyroidism in Korea. As the minimally invasive approach for parathyroidectomy has replaced bilateral neck exploration, clinicians need to be aware of the possibility of concomitant PTC. We would like to thank Candemir et al. for their helpful comments based on an accurate understanding of this study's clinical implications.

\section{CONFLICTS OF INTEREST}

No potential conflict of interest relevant to this article was reported.

\section{ORCID}

Chaiho Jeong https://orcid.org/0000-0002-2914-2278

Jeonghoon Ha https://orcid.org/0000-0001-9219-7135

\section{REFERENCES}

1. Jeong C, Kwon HI, Baek H, Kim HS, Lim DJ, Baek KH, et al. Association of hyperparathyroidism and papillary thyroid cancer: a multicenter retrospective study. Endocrinol Metab (Seoul) 2020;35:925-32.

2. Shin JH, Baek JH, Chung J, Ha EJ, Kim JH, Lee YH, et al. Ultrasonography diagnosis and imaging-based management of thyroid nodules: revised Korean Society of Thyroid Radiology Consensus Statement and Recommendations. Korean J Radiol 2016;17:370-95.

3. Song YS, Lim JA, Park YJ. Mutation profile of well-differentiated thyroid cancer in Asians. Endocrinol Metab (Seoul) 2015;30:252-62.

4. Song YS, Park YJ. Genomic characterization of differentiated thyroid carcinoma. Endocrinol Metab (Seoul) 2019;34:110. 